\title{
Earlier switching from intravenous to oral antibiotics owing to electronic reminders
}

\author{
Beeler, Patrick E ; Kuster, Stefan P ; Eschmann, Emmanuel ; Weber, Rainer ; Blaser, Jürg
}

\begin{abstract}
Paper-based interventions have been shown to stimulate switching from intravenous (i.v.) to oral (p.o.) antibiotic therapies. Shorter i.v. durations are associated with a lower risk of iatrogenic infections as well as reduced workload and costs. The purpose of this study was to determine whether automated electronic reminders are able to promote earlier switching. In this controlled before-and-after study, an algorithm identified patients who were eligible for i.v.-to-p.o. switch $60 \mathrm{~h}$ after starting i.v. antimicrobials. Reminders offering guidance on the re-assessment of initial i.v. therapy were displayed within the electronic health records in 12 units during the intervention period (year 2012). In contrast, no reminders were visible during the baseline period (2011) and in the control group (17 units). A total of 22863 i.v. antibiotic therapies were analysed; $6082(26.6 \%)$ were switched to p.o. THERAPY: In the intervention group, 757 courses of i.v. antibiotics were administered for a mean \pm standard deviation duration of $5.4 \pm 8.1$ days before switching to p.o. antibiotics in the baseline period, and 794 courses for $4.5 \pm 5.5$ days in the intervention period $(\mathrm{P}=0.004)$, corresponding to a $17.5 \%$ reduction of i.v. administration time. In contrast, in the control group the duration increased; 2240 i.v. antibiotics were administered for a mean duration of $4.0 \pm 5.9$ days in the baseline period, and 2291 for $4.3 \pm 5.8$ days in the intervention period $(\mathrm{P}=0.03)$. Electronic reminders fostered earlier i.v.-to-p.o. switches, thereby reducing the duration of initial i.v. therapies by nearly a day.
\end{abstract}

DOI: https://doi.org/10.1016/j.ijantimicag.2015.06.013

Posted at the Zurich Open Repository and Archive, University of Zurich

ZORA URL: https://doi.org/10.5167/uzh-114672

Journal Article

Accepted Version

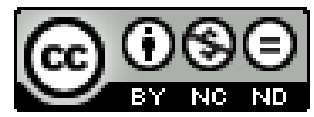

The following work is licensed under a Creative Commons: Attribution-NonCommercial-NoDerivatives 4.0 International (CC BY-NC-ND 4.0) License.

Originally published at:

Beeler, Patrick E; Kuster, Stefan P; Eschmann, Emmanuel; Weber, Rainer; Blaser, Jürg (2015). Earlier switching from intravenous to oral antibiotics owing to electronic reminders. International Journal of Antimicrobial Agents, 46(4):428-433.

DOI: https://doi.org/10.1016/j.ijantimicag.2015.06.013 


\section{Earlier Switching from Intravenous to Oral Antibiotics}

\section{Due to Electronic Reminders}

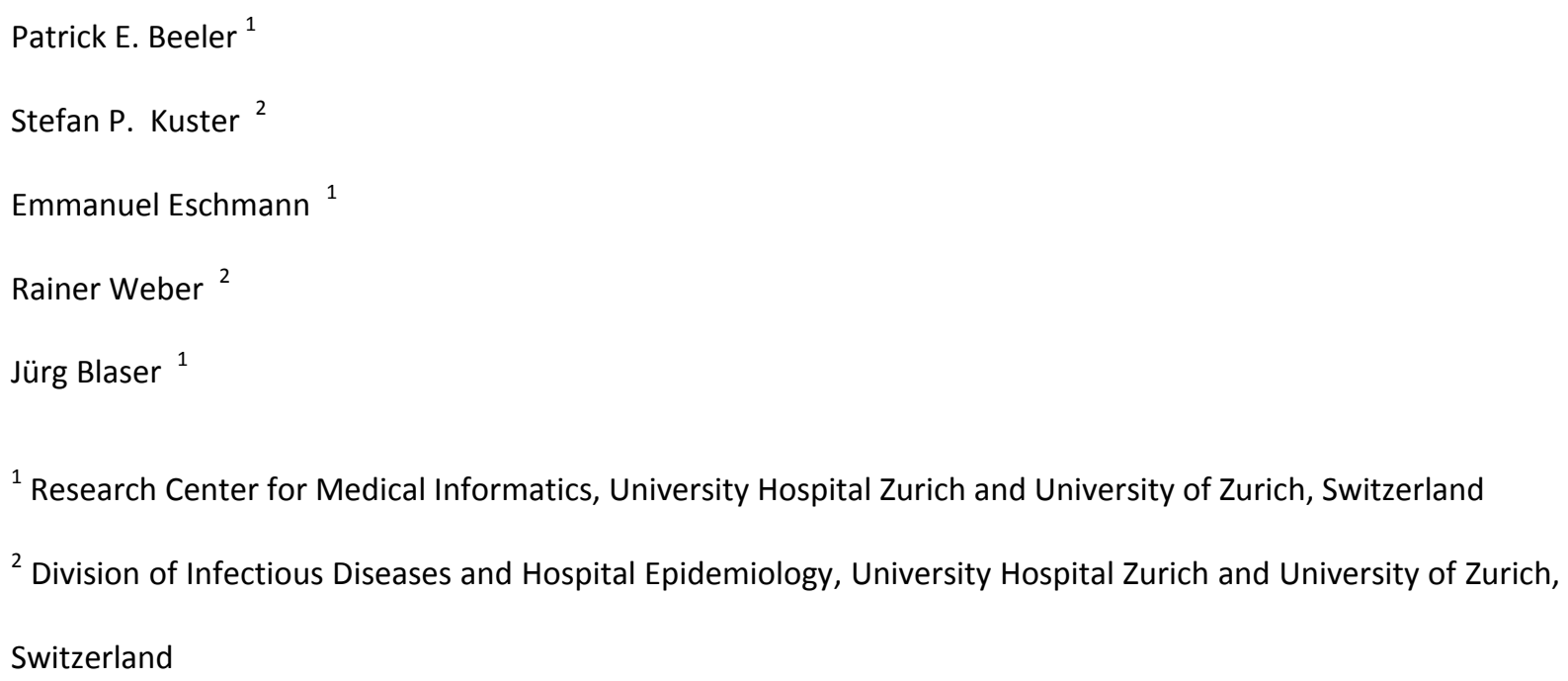

\section{Correspondence}

Prof. Dr. Jürg Blaser, Research Center for Medical Informatics, Directorate of Research \& Education, University Hospital Zurich, Universitiy of Zurich, Moussonstrasse 2, CH-8091 Zurich, Switzerland Phone: +41 44255 3618; Fax: +41446345503

juerg.blaser@usz.ch

\section{Running Title}

eReminder fostering early IV-PO switches

\section{Keywords}

(i) Anti-Infective Agents/administration \& dosage*

(ii) Decision Support Systems, Clinical*

(iii) Medical Informatics

(iv) Reminder Systems*

(v) Anti-Bacterial Agents* 


\section{Abstract}

Paper-based interventions have been shown to stimulate switching from intravenous (IV) to oral (PO) antibiotic therapies. Shorter IV durations are associated with a lower risk for iatrogenic infections, reduced workload and costs. The purpose of this study was to determine whether automated electronic reminders are able to promote earlier switching.

In this controlled before-and-after-study, an algorithm identified patients who were eligible for IV-PO switches 60 hours after starting IV antimicrobial therapies. Reminders offering guidance on the reassessment of the initial IV therapy were displayed within the electronic health records in 12 units during the intervention period (year 2012). In contrast, no reminders were visible during the baseline period (2011) and in the control group (17 units).

A total of 22,863 IV antibiotic therapies were analysed, and 6,082 (26.6\%) were switched to PO. In the intervention group, 757 courses of IV antibiotics were administered for a mean duration ( \pm standard deviation) of $5.4( \pm 8.1)$ days before switching to PO in the baseline period and 794 courses for $4.5( \pm 5.5)$ days in the intervention period $(p=0.004)$, corresponding to a $17.5 \%$ reduction of the IV administration time. In contrast, in the control group the duration increased; 2,240 IV antibiotics were administered for a mean duration of 4.0 $( \pm 5.9)$ days in the baseline period and 2,291 for $4.3( \pm 5.8)$ days in the intervention period $(p=0.03)$.

Electronic reminders fostered earlier IV-PO switches, thereby reducing the duration of the initial IV therapies by nearly a day.

The study was registered at ClinicalTrials.gov (NCT01499927). 
Studies have shown that antimicrobial therapies among hospitalised patients are inappropriate in $30-50 \%$ of the time (1-4). Antimicrobial stewardship programs intend to optimize the use of antimicrobial agents, curb resistance, minimize the risk of adverse effects and reduce costs $(2,4)$.

One strategy to improve antimicrobial regimens is earlier switching from intravenous (IV) to the oral (PO) route of administration $(4,5)$. Such IV-PO switches are often considered approximately three days after starting the empiric therapy if the patient is clinically stable and is able to swallow $(6,7)$. Changing the administration route may be performed while ordering the same or a different antimicrobial agent, depending on the microbiological susceptibility results. Important advantages are associated with an early IV-PO switch: Lower risk of catheter-associated infections, reduced nursing workload, and decreased direct and indirect costs $(5,7-9)$. A number of studies demonstrated reduced durations of the initial IV therapies due to paperbased checklists fostering the IV-PO switch (9-11).

Dellit et al. (4) and Pestotnik (12) summarized the literature on computer-based decision support for antimicrobial stewardship purposes. One study investigated a commercial decision support system that generated various alerts to reduce inappropriate antimicrobial use, e.g. suggested switches to equivalent oral agents (13). Other investigators presented a sophisticated algorithm that recommended the oral administration route for quinolones in some patients, and successfully increased the use of PO administration of levofloxacin and ciprofloxacin (14). Shojania et al. (15) displayed guidelines at the time of computerized physician order entry and thereby reduced the duration of IV vancomycin.

The aim of the present clinical trial was to encourage early IV-PO switches using computerized clinical decision support (CDS) in order to reduce the duration of the initial IV therapy of antimicrobials. Since 'alert fatigue' is a well-known issue in electronic approaches (16), the algorithm featured enhanced specificity by checking in real time whether patient parameters allowed for switching from IV to PO. 


\section{Materials and Methods}

\subsection{Design and Site}

The study was designed as a prospective, controlled before-and-after trial. The baseline period lasted from $1 / 1 / 2011-12 / 31 / 2011$, the intervention period from $1 / 1 / 2012-12 / 31 / 2012$. These study periods were defined in order to mitigate seasonal influences on infectious diseases (17). No reminders were displayed during the baseline period and in the control group. In the intervention group, the reminders were activated at the beginning of the intervention period.

The University Hospital Zurich has approximately 850 beds and covers all specialties except for orthopedic surgery and pediatrics. All inpatients receiving IV antimicrobials ordered via computerized physician order entry were included. A total of 29 units of the hospital cared for inpatients during the study periods.

The allocation of the 29 inpatient units to either the intervention or the control group was based on feasibility and safety considerations by infectious diseases specialists. 12 units served as intervention group (angiology, cardiology, endocrinology \& diabetology, gastroenterology, immunology, infectious diseases, internal medicine, nephrology, neurology, pulmonology, rheumatology, urology), 17 as control group (abdominal surgery, cardiac \& vascular surgery, dermatology, gynecology, hematology, neonatology, neuroradiology, neurosurgery, obstetrics, oncology, ophthalmology, oral and maxillofacial surgery, otolaryngology, radiation oncology, reconstructive surgery, thoracic surgery, traumatology). It was clear from the beginning that the two study groups would not be comparable due to differences between the patient populations. We controlled for this issue by comparing the baseline period with the intervention period in both study groups separately.

The ethics committee approved the study and patient consent was waived. Under consideration of anticipated improvements due to the intervention (increase patient safety, reduce workload and costs) $(2,4,5$, 7-9) and of available studies with similar interventions that reported no higher incidence of adverse events, (9, $11,13,18)$ a waiver for informed consent was requested, because (i) limiting the study to patients who could give informed consent would decrease the generalizability of the results, and (ii) even attempting to obtain informed consent from such a large number of patients would result in financial costs that are prohibitive and a potentially poor use of limited resources. The study was registered at ClinicalTrials.gov (NCT01499927). 


\subsection{Clinical Information System}

Inpatient care is comprehensively documented and managed by the clinical information system (Kisim, Cistec AG, Zurich, Switzerland) including all pharmacological therapies, other treatments and diagnostic procedures on all wards except for intensive care units (ICUs).

\subsection{Computerized Reminders}

60 hours after start of an IV antimicrobial therapy, an algorithm automatically checked whether: (i) the therapy was scheduled for an additional 24 hours or longer, (ii) neutrophil count of the patient exceeded $0.5 \mathrm{G} / \mathrm{l}$, (iii) body temperature was below $38^{\circ} \mathrm{C}$, and (iv) patient had the ability to swallow as indicated by orders of PO medication. If the conditions were met, a non-interruptive reminder was displayed as a red bar within the top section of the electronic health record.

By clicking on the reminder bar a window appeared, offering guidance on whether or not an IV-PO switch was appropriate: At first, the window contained a short explanation why the reminder was displayed. Further, it recommended reassessing the initial IV treatment under consideration of five suggestions: (a) switching from IV to PO, (b) narrowing the antimicrobial spectrum, (c) stopping the antimicrobial treatment if no longer indicated, (d) no change, or (e) consulting an infectious diseases specialist. At last, a table listed the need-toknows about the advantages of IV-PO switches, when a switch was possible, and also contraindications to switch.

The reminder was displayed in the electronic health record from 60 hours onwards until a physician acknowledged the notification, or the IV therapy triggering the reminder was stopped. However, the reminder was automatically terminated 10 days after it appeared. Therefore, the immediate influence of the reminders is considered to be reflected by IV-PO switches during the time frame of 60-300 hours.

\subsection{Definition of 'Switch'}

Antimicrobials were defined using the Anatomical Therapeutic Chemical (ATC) classification system (World Health Organization, Geneva, Switzerland). Drug orders according to ATC codes of the categories J01 (antibiotics), J02 (antifungals), J04 (antimycobacterials), and J05 (antivirals) were included.

The only 'antimycobacterial' ordered was rifampicin (rifampin). However, IV rifampicin - switched to PO in the process - was always used, and therefore considered, as an antibiotic and never prescribed for the treatment of tuberculosis or leprosy during the study. 
At the end of an IV antimicrobial therapy, the time frame 'IV stop time \pm 12 hours' was used to check for a 'PO start time': If the stopped IV therapy and the starting PO therapy were among the same ATC category, then had an IV-PO switch been performed by definition. Only throughout the hospital stay were durations of IV and PO administrations considered.

\subsection{Statistics}

Continuous variables were presented as means ( \pm standard deviation). Comparisons of the durations of therapies and tests of Kaplan-Meier curve differences were performed using the log-rank test. Levels of $p \leq 0.05$ were considered statistically significant. Kaplan-Meier curves were plotted for IV-PO switches that reflected the reminders' impact, i.e. within the time frame 60-300 hours.

The primary end point was the duration of IV administration of antimicrobial therapies until switching to PO administration. Secondary analyses included changes of numbers and durations of switched antibiotics. Further, secondary end points were IV-PO switches within 60-300 in the years 2011 and 2012.

Calculations were performed using R, version 3.0.2 (R Foundation for Statistical Computing, Vienna, Austria). 


\section{Results}

A total of 74,766 patients were hospitalized during the two study periods (Tab. 1). Of 24,599 IV prescriptions for antimicrobials, 6,410 (26.1\%) were switched to PO. These 6,410 IV-PO switches were analysed in detail:

\subsection{Total IV-PO switches of antimicrobials}

Overall, the reminders reduced the mean IV duration among the IV-PO switches by $18.1 \%$ (23.7 hours): In the intervention group, 780 IV therapies were administered for a mean duration ( \pm standard deviation) of 5.44 $( \pm 8.13)$ days before they were switched to $\mathrm{PO}$ in the baseline period, and 824 courses for $4.46( \pm 5.45)$ days in the intervention period $(p=0.0021)$. In the control group, 2,374 IV therapies were administered for a mean duration of $4.26( \pm 6.24)$ days during the baseline period, and 2,432 courses for $4.48( \pm 5.99)$ days in the intervention period $(p=0.096)$.

\subsection{IV-PO switched antibiotics}

Antibiotics accounted for $95 \%$ of switched antimicrobials, and they were most often switched to the same PO agent where reasonable (Tab. 2). In the intervention group, 757 IV antibiotics were administered for a mean duration of $5.42( \pm 8.15)$ days before switching to PO in the baseline period, and 794 courses for 4.47 $( \pm 5.49)$ days in the intervention period $(p=0.0036)$, corresponding to a $17.5 \%(22.8$ hours) reduction of the IV administration time (Tab. 3). In contrast, in the control group, 2,240 IV antibiotics were administered for a mean duration of $3.96( \pm 5.86)$ days in the baseline period, whereas the mean IV duration of 2,291 courses increased in the intervention period to $4.28( \pm 5.83)$ days before they were switched to PO $(p=0.032)$.

Among the three IV antibiotics with the highest volumes of orders (Tab. 2), the reminders mainly affected the switches of IV piperacillin/tazobactam, reducing the mean IV duration by 2.3 days following the intervention (Tab. 3), whereas in the control group the IV duration of piperacillin/tazobactam remained stable at roughly 7 days. In contrast, the mean IV durations of amoxicillin/clavulanic acid and ceftriaxone were sparsely reduced due to the reminders. The mean IV duration of ceftriaxone in the intervention group decreased by 0.03 days to $3.83( \pm 3.04)$ days during the intervention period (baseline: 166 IV courses; intervention period: 171). 
The analysis of those IV antibiotics that were switched while displaying reminders (60-300 hours; Fig. 1) revealed a decrease of the mean duration of the IV therapies in the intervention group: During the baseline period, 431 IV therapies lasted $5.17( \pm 2.32)$ days until switching, compared to 452 IV therapies during the intervention period which had a mean duration of $4.78( \pm 1.95)$ days until switching $(p=0.0059)$. Analysing the same time frame in the control group, no change between the baseline and the intervention period was observed (Fig. 1): The mean duration of the initial IV antibiotics was $5.20( \pm 2.36)$ days during the baseline and $5.19( \pm 2.37)$ days during the intervention period, the numbers of switched antibiotics were 1,060 and 1,069 , respectively $(p=0.88)$.

\subsection{IV-PO switched antifungals and antivirals}

In the intervention group, the numbers of IV-PO switched antifungals and antivirals were low: During the baseline period, 9 antifungals had a mean IV duration of $0.78( \pm 1.04)$ days, and during the intervention period, 16 had an IV duration of $3.46( \pm 5.10)$ days $(p=0.30)$. The IV administrations of 14 antivirals lasted $9.67( \pm 8.43)$ days during the baseline, and 14 IV antivirals were switched after $4.79( \pm 3.30)$ days during the intervention period $(p=0.024)$. However, after reviewing the respective electronic health records, causality between the electronic reminders and the reduced IV duration of antivirals appeared to be unlikely. No changes of the IV durations of antifungals and antivirals were observed in the control group. 


\section{Discussion}

We found that the electronic intervention reduced the mean duration of the initial IV administration of antimicrobials by nearly a day until they were switched to PO. Meanwhile in the control group, where the reminders had been suppressed, the duration of the initial IV antimicrobial therapies did not change.

The antibiotic that contributed most to the observed effect was piperacillin/tazobactam. Its mean IV duration decreased in the intervention group by 2.3 days, whereas in the control group the IV administration time remained stable at roughly 7 days. Surprisingly, the other switched antibiotics out of the top three in terms of high ordering volumes, amoxicillin/clavulanic acid and ceftriaxone, were barely affected by the reminders. The relatively short IV durations of these antimicrobials may explain this finding in part. Additionally, figure 1 shows that some time was required to impact, since firstly the providers needed time to see the reminders and change the orders, and subsequently the nurses had to implement the modifications towards the end of the current dosing intervals. Therefore displaying the reminders earlier than 60 hours after the start of the IV therapy could be considered for the hospital-wide rollout of the concept.

Various approaches influencing the prescribing behavior of health care professionals have been studied $(13,19,20)$. A recent trial investigated the impact of phone calls to stimulate IV-PO switches of clindamycin, levofloxacin and paracetamol (21). Others used recommendations from a peer team to reduce the IV duration of antibiotics (vancomycin, tobramycin, ceftazidime, ampicillin/sulbactam, ciprofloxacin, cefuroxime, imipenem/cilastatin, cilastatin, fluconazole, cefotetan, and ceftriaxone) (22). Another group analysed the impact of a paper-based intervention encouraging early switches of antibiotics on day three of IV therapy, without further restrictions to specific agents (9). The trial was designed as a before-and-after study, but lacked a control group. The authors presented a reduction of the median IV duration by $19 \%$ after adjusting for confounders (9).

Some research groups investigated electronic interventions to decrease unnecessary use of IV medications. Shojania et al. (15) performed a randomized controlled trial and successfully reduced the number and duration of vancomycin prescriptions by displaying electronic guidelines at the time of order entry. Providers in both study groups were electronically prompted to renew or discontinue vancomycin after 72 hours (15). Fischer et al. (23) performed a before-and-after study without control group and electronically promoted IV-PO switches of six medications using CDS (fluconazole, levofloxacin, metronidazole, ranitidine, amiodarone, ketorolac). The 
authors presented data on the decreased use of the IV administration of the drugs (23). Hulgan et al. (14) performed a before-and-after study without control group, and analysed the PO use of levofloxacin and ciprofloxacin when displaying electronic notifications. The use of PO levofloxacin and PO ciprofloxacin increased following the intervention (14). The studies by Fischer et al. (23) and Hulgan et al. (14) implemented sophisticated algorithms that searched the electronic patient charts for PO orders or structured data on oral diets in order to avoid alerts in patients who are unable to swallow. Our algorithm also searched for active PO orders to identify patients with functioning gastrointestinal system. This feature increases the specificity of electronic notifications, additionally concentrates the impact of the intervention on early switching to PO, and decreases the risk for alert fatigue (16).

We performed a prospective, hospital-wide, before-and-after study with an intervention and a control group. The non-interruptive reminders offered guidance on whether or not to switch from IV to PO. The information presented in the pop-up window was provided unobtrusively with intent, since CDS must not preempt the considerations and decisions of the physicians on duty (24). Our study included large samples of patients and antimicrobial therapies, and two entire years were analysed. Data of frequently IV-PO switched antibiotics are presented as well as a comprehensive overview of the IV duration changes of severely influenced antibiotic agents, which may be an important input for future developments. To date, no 'stoporders' are implemented at our institution, allowing for the accurate calculation of the genuine durations of IV and PO administrations.

Several limitations need to be taken into account in interpreting our results. Firstly, the study was not a randomized trial. However, we used a pre-/post-intervention study design including a control group, which is among the most reliable designs of quasi-experimental studies (25). Increasingly used study designs such as interrupted time series analyses $(26,27)$ and stepped wedge cluster randomised trials $(28,29)$ should be considered for future investigations. Secondly, the clinical outcome was not assessed, and thus it remains unknown whether the number of catheter-associated infections and other clinical end points were affected by the reminders. Finally, although the study was carefully conducted, without any reported unintended consequences, we cannot completely rule out problematic switches due to the CDS intervention. Nevertheless, Mertz et al. (9) determined the safety of a similar intervention and observed no higher incidence of adverse events, as did others $(11,13,18)$. 
The present findings have important implications, since a lower risk for catheter-associated infections, reduced nursing workload, and decreased direct and indirect costs are associated with early IV-PO switches (4, 5, 7-9). The proposed CDS algorithm allows for the implementation in most inpatient specialties with an openend intervention period; no manpower is required for the continued operation of the electronic reminders within the clinical information system, and a similar reminder could also be implemented in other hospitals.

Not all switched antimicrobial agents were strongly affected by the reminders, and research is needed to investigate how and to which extent these IV therapies could positively be influenced. However, some patients require aggressive IV antimicrobial treatments (9), e.g. patients with cystic fibrosis, and particularly lung transplant recipients often present with complex infections (30). Yet, the potential of CDS in such specific clinical settings is unknown. Finally, large studies evaluating similar CDS interventions are suggested to investigate clinical end points, because the most important research question remains, whether CDS is able to improve patient outcomes.

\section{Conclusion}

The electronic reminders promoted earlier IV-PO switching of antibiotics, thereby reducing the duration of the initial IV therapies by nearly a day. 


\section{Acknowledgements}

Parts of the data were shown during an oral presentation at the Swiss eHealth Summit 2014 in Bern, Switzerland, and an abstract was presented at the AMIA Annual Meeting 2014 in Washington, D.C., USA.

We thank Markus Berger (Cistec AG, Zurich) for the programming of the reminder algorithm.

\section{Funding Statement}

This research received no specific grant from any funding agency in the public, commercial or not-for-profit sectors.

\section{Transparency Declaration}

None to declare.

Author contributions: P. E. Beeler designed and performed the research, analysed and interpreted data, and wrote the manuscript. S. P. Kuster and E. Eschmann performed research, interpreted data, and reviewed the manuscript. R. Weber designed the research, interpreted data, and reviewed the manuscript. J. Blaser designed the research, analysed and interpreted data, and reviewed the manuscript. All authors approved the final submitted version of the manuscript. 
Table 1: Number of patients, mean length of hospital stay, mean age, and proportion of females in the study groups during the baseline and the intervention period.

\begin{tabular}{|c|c|c|c|c|c|c|c|}
\hline & & $\begin{array}{l}\text { Number of } \\
\text { patients }\end{array}$ & $\begin{array}{l}\text { Mean length of } \\
\text { hospital stay [days] }\end{array}$ & (SD) & $\begin{array}{l}\text { Mean age of } \\
\text { patients [years] }\end{array}$ & (SD) & $\begin{array}{l}\text { Proportion of } \\
\text { female patients [\%] }\end{array}$ \\
\hline \multirow{2}{*}{$\begin{array}{l}\text { Intervention } \\
\text { group }\end{array}$} & $\begin{array}{l}\text { Baseline period } \\
\text { (2011) }\end{array}$ & 10,441 & 6.2 & $( \pm 8.3)$ & 61.4 & $( \pm 16.8)$ & 38.7 \\
\hline & $\begin{array}{l}\text { Intervention } \\
\text { period (2012) }\end{array}$ & 10,410 & 6.5 & $( \pm 9.1)$ & 61.8 & $( \pm 17.0)$ & 38.0 \\
\hline \multirow{2}{*}{ Control group } & $\begin{array}{l}\text { Baseline period } \\
\text { (2011) }\end{array}$ & 26,768 & 7.0 & $( \pm 10.8)$ & 45.2 & $( \pm 24.1)$ & 54.9 \\
\hline & $\begin{array}{l}\text { Intervention } \\
\text { period (2012) }\end{array}$ & 27,147 & 6.9 & $( \pm 10.6)$ & 45.2 & $( \pm 24.2)$ & 54.3 \\
\hline
\end{tabular}

SD: Standard deviation. 
Table 2: Top 10 IV antibiotics in terms of ordering volume, later switched to PO. Only unambiguous (one-to-one) switches were considered. Numbers are presented as totals of both study periods and study groups. For each IV antibiotic the two most common PO switches are listed.

\begin{tabular}{|c|c|c|c|c|c|c|c|c|c|c|}
\hline $\begin{array}{l}\text { Top } 10 \text { most frequently } \\
\text { started IV antibiotics that } \\
\text { were switched in the } \\
\text { process }\end{array}$ & $\begin{array}{l}\text { Mean IV } \\
\text { duration } \\
\text { [days] }\end{array}$ & SD & $\begin{array}{c}\text { Number } \\
\text { of IV } \\
\text { orders }\end{array}$ & $\begin{array}{l}\% \text { of IV } \\
\text { orders }\end{array}$ & & $\begin{array}{l}\text { Most often switched to } \\
\text { these PO antibiotics }\end{array}$ & $\begin{array}{l}\text { Mean } \\
\text { PO } \\
\text { duration } \\
\text { [days] }\end{array}$ & SD & $\begin{array}{l}\text { Number } \\
\text { of PO } \\
\text { orders }\end{array}$ & $\begin{array}{l}\text { \% switched } \\
\text { to this PO } \\
\text { antibiotic } \\
\text { (\#PO / \#IV) }\end{array}$ \\
\hline \multirow{2}{*}{ Amoxicillin/clavulanic acid } & \multirow{2}{*}{3.1} & \multirow{2}{*}{2.99} & \multirow{2}{*}{2709} & \multirow{2}{*}{47.3} & $\rightarrow$ & Amoxicillin/clavulanic acid & 2.79 & 3.12 & 2554 & 94.3 \\
\hline & & & & & $\rightarrow$ & Ciprofloxacin & 4.54 & 4.6 & 62 & 2.3 \\
\hline \multirow{2}{*}{ Piperacillin/tazobactam } & \multirow{2}{*}{6.67} & \multirow{2}{*}{8} & \multirow{2}{*}{750} & \multirow{2}{*}{13.1} & $\rightarrow$ & Amoxicillin/clavulanic acid & 2.62 & 3.25 & 391 & 52.1 \\
\hline & & & & & $\rightarrow$ & Ciprofloxacin & 3.58 & 4.87 & 259 & 34.5 \\
\hline \multirow{2}{*}{ Ceftriaxone } & \multirow{2}{*}{4.21} & \multirow{2}{*}{4.76} & \multirow{2}{*}{401} & \multirow{2}{*}{7} & $\rightarrow$ & Amoxicillin/clavulanic acid & 2.38 & 2.2 & 178 & 44.4 \\
\hline & & & & & $\rightarrow$ & Ciprofloxacin & 2.78 & 3.6 & 103 & 25.7 \\
\hline \multirow{2}{*}{ Cefuroxime } & \multirow{2}{*}{1.33} & \multirow{2}{*}{1.5} & \multirow{2}{*}{337} & \multirow{2}{*}{5.9} & $\rightarrow$ & Cefuroxime & 2.27 & 1.54 & 319 & 94.7 \\
\hline & & & & & $\rightarrow$ & Amoxicillin/clavulanic acid & 1.61 & 0.76 & 6 & 1.8 \\
\hline \multirow{2}{*}{ Ciprofloxacin } & \multirow{2}{*}{2.77} & \multirow{2}{*}{3.23} & \multirow{2}{*}{313} & \multirow{2}{*}{5.5} & $\rightarrow$ & Ciprofloxacin & 4.46 & 5.69 & 292 & 93.3 \\
\hline & & & & & $\rightarrow$ & Clindamycin & 5.88 & 4.32 & 5 & 1.6 \\
\hline \multirow{2}{*}{ Clindamycin } & \multirow{2}{*}{3.21} & \multirow{2}{*}{4.13} & \multirow{2}{*}{158} & \multirow{2}{*}{2.8} & $\rightarrow$ & Clindamycin & 2.74 & 3.07 & 135 & 85.4 \\
\hline & & & & & $\rightarrow$ & Amoxicillin/clavulanic acid & 1.4 & 0.87 & 7 & 4.4 \\
\hline \multirow{2}{*}{ Meropenem } & \multirow{2}{*}{11.4} & \multirow{2}{*}{13.21} & 150 & 26 & $\rightarrow$ & Ciprofloxacin & 3.81 & 3.87 & 48 & 32 \\
\hline & & & 150 & 2.0 & $\rightarrow$ & Amoxicillin/clavulanic acid & 3.64 & 3.67 & 44 & 29.3 \\
\hline Vancomycin & 975 & 1262 & 128 & 22 & $\rightarrow$ & Ciprofloxacin & 5.95 & 7.93 & 27 & 21.1 \\
\hline vancominy & 0.15 & 12.02 & $1<0$ & 2.2 & $\rightarrow$ & Amoxicillin/clavulanic acid & 2.74 & 2.19 & 19 & 14.8 \\
\hline Metronidazole & 3.49 & 250 & 106 & 10 & $\rightarrow$ & Ciprofloxacin & 2.95 & 3.55 & 53 & 50 \\
\hline IVIetromaazore & 3.49 & 2.59 & 100 & 1.9 & $\rightarrow$ & Amoxicillin/clavulanic acid & 2.41 & 2.45 & 35 & 33 \\
\hline Cefazolin & 236 & 331 & 84 & 15 & $\rightarrow$ & Amoxicillin/clavulanic acid & 3.05 & 2.89 & 40 & 47.6 \\
\hline 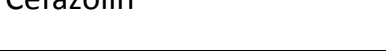 & 2.00 & 3.01 & 84 & 1.0 & $\rightarrow$ & Ciprofloxacin & 5.3 & 2.67 & 11 & 13.1 \\
\hline
\end{tabular}

SD: Standard deviation.

IV-PO switches are presented in this table explicitly for unambiguous (one-to-one) switches only: These switches were defined as one IV antimicrobial switched to one PO antimicrobial (representing $94 \%$ of all switches). 
Table 3: Change of the mean IV duration from the baseline (2011) to the intervention period (2012) of the top 10 antibiotics according to the weighted change in the intervention group. Only antibiotics that were prescribed at least 5 times during both study periods have been included in the top 10 list.

\begin{tabular}{|c|c|c|c|c|c|c|c|c|c|c|c|c|}
\hline & & \multirow{2}{*}{\multicolumn{4}{|c|}{2011}} & \multirow{2}{*}{\multicolumn{4}{|c|}{2012}} & & \multirow{3}{*}{$\begin{array}{l}\text { Weighted } \\
\text { change }^{1)} \\
\text { [days] }\end{array}$} \\
\hline & & & & & & & & & & & & \\
\hline & Antibiotic & $\begin{array}{l}\text { Mean IV } \\
\text { duration [days] }\end{array}$ & SD & $n$ & $\%$ & $\begin{array}{l}\text { Mean IV } \\
\text { duration [days] }\end{array}$ & SD & $n$ & $\%$ & $\begin{array}{l}\text { Change o } \\
\text { [days] (ch } \\
\text { percenta }\end{array}$ & an duration & \\
\hline \multirow{12}{*}{ 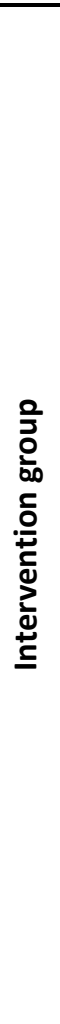 } & Piperacillin/tazobactam & 7.56 & 13.2 & 163 & 21.5 & 5.26 & 5.29 & 170 & 21.4 & -2.3 & $(-30.4 \%)$ & -383.0 \\
\hline & Imipenem/cilastatin & 12.12 & 7.98 & 8 & 1.1 & 6.75 & 7.25 & 8 & 1 & -5.37 & $(-44.3 \%)$ & -43.0 \\
\hline & Vancomycin & 7.63 & 9.14 & 16 & 2.1 & 5.77 & 6.74 & 23 & 2.9 & -1.86 & $(-24.4 \%)$ & -36.3 \\
\hline & Teicoplanin & 14.34 & 12.48 & 14 & 1.8 & 11.3 & 11.96 & 5 & 0.6 & -3.04 & $(-21.2 \%)$ & -28.9 \\
\hline & Amoxicillin & 9.31 & 6.06 & 6 & 0.8 & 6.28 & 5.4 & 6 & 0.8 & -3.03 & $(-32.6 \%)$ & -18.2 \\
\hline & Ertapenem & 5.26 & 4.66 & 8 & 1.1 & 3.93 & 2.66 & 19 & 2.4 & -1.33 & $(-25.3 \%)$ & -18.0 \\
\hline & Sulfamethoxazole/trimethoprim & 5.09 & 5.09 & 11 & 1.5 & 3.12 & 2.39 & 6 & 0.8 & -1.97 & $(-38.7 \%)$ & -16.7 \\
\hline & Metronidazole & 4.07 & 3.41 & 7 & 0.9 & 2.77 & 2.88 & 10 & 1.3 & -1.3 & $(-31.9 \%)$ & -11.1 \\
\hline & Ciprofloxacin & 2.45 & 2.2 & 43 & 5.7 & 2.21 & 2.52 & 45 & 5.7 & -0.24 & $(-9.8 \%)$ & -10.6 \\
\hline & Amoxicillin/clavulanic acid & 3.56 & 3.13 & 189 & 25 & 3.51 & 3.64 & 204 & 25.7 & -0.05 & $(-1.4 \%)$ & -9.8 \\
\hline & Other antibiotics & 5.11 & 6.43 & 292 & 38.6 & 4.83 & 6.61 & 298 & 37.5 & -0.28 & $(-5.5 \%)$ & -82.6 \\
\hline & Total & 5.42 & 8.15 & 757 & 100 & 4.47 & 5.49 & 794 & 100 & -0.95 & $(-17.5 \%)$ & -736.7 \\
\hline
\end{tabular}

SD: Standard deviation.

${ }^{1)}$ Estimated mean reduction of IV days per year, defined as follows:

Weighted change $=$ change of mean duration $*\left(\left(n_{2011}+n_{2012}\right) / 2\right)$ 

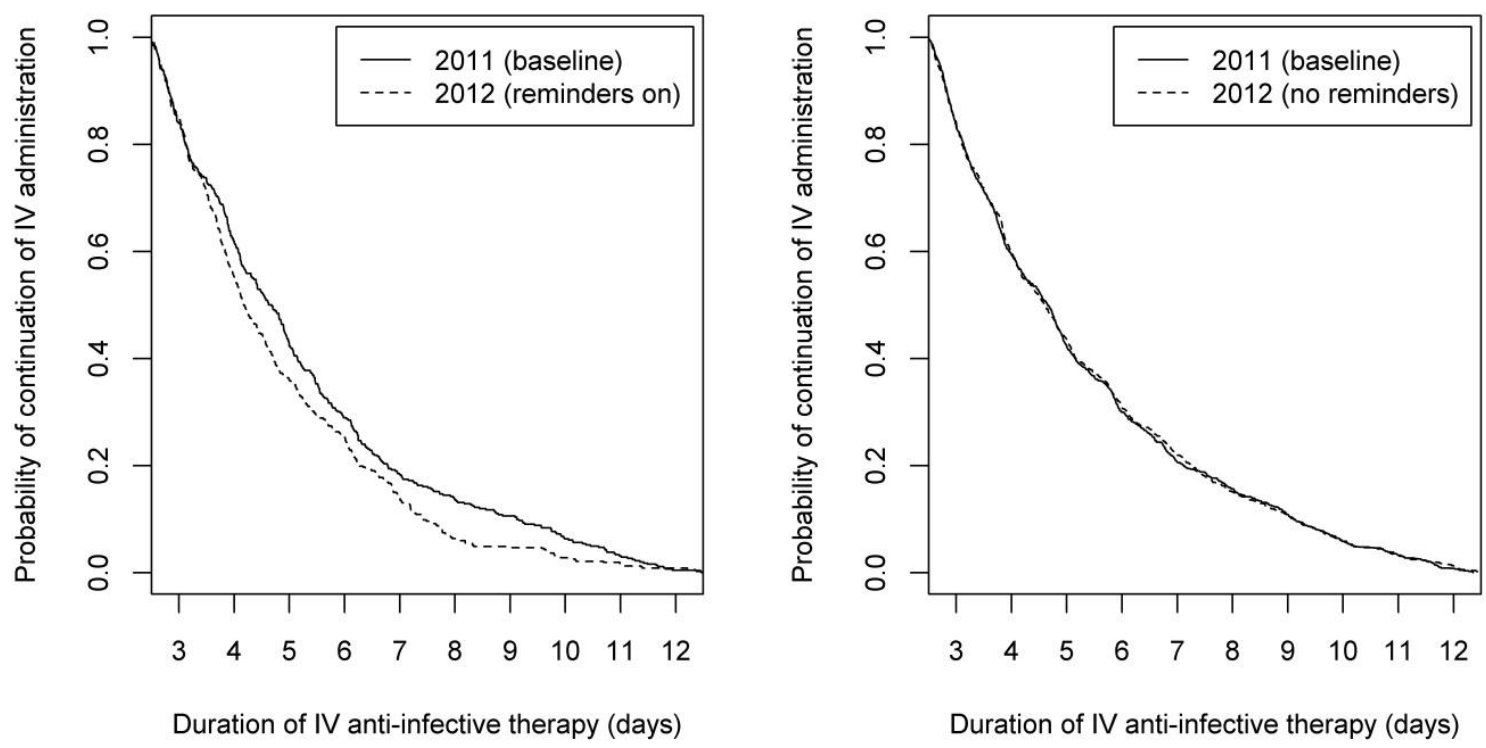

Figure 1: Kaplan-Meier curves of the durations of IV antibiotic therapies that were switched to PO within the time frame of 60-300 hours in the intervention group (left; $p=0.0059$ ) and control group (right; $p=0.88$ ). 


\section{References}

1. Hecker MT, Aron DC, Patel NP, Lehmann MK, Donskey CJ. Unnecessary use of antimicrobials in hospitalized patients: current patterns of misuse with an emphasis on the antianaerobic spectrum of activity. Arch Intern Med. 2003;163(8):972-8.

2. Davey P, Brown E, Charani E, Fenelon L, Gould IM, Holmes A, et al. Interventions to improve antibiotic prescribing practices for hospital inpatients. Cochrane Database Syst Rev. 2013;4:CD003543.

3. Cusini A, Rampini SK, Bansal V, Ledergerber B, Kuster SP, Ruef C, et al. Different patterns of inappropriate antimicrobial use in surgical and medical units at a tertiary care hospital in Switzerland: a prevalence survey. PloS one. 2010;5(11):e14011.

4. Dellit TH, Owens RC, McGowan JE, Jr., Gerding DN, Weinstein RA, Burke JP, et al. Infectious Diseases Society of America and the Society for Healthcare Epidemiology of America guidelines for developing an institutional program to enhance antimicrobial stewardship. Clinical Infectious Diseases. 2007;44(2):159-77.

5. van Niekerk AC, Venter DJ, Boschmans SA. Implementation of intravenous to oral antibiotic switch therapy guidelines in the general medical wards of a tertiary-level hospital in South Africa. $J$ Antimicrob Chemother. 2012;67(3):756-62.

6. Roger PM, Labate C, Serre S, Zumbo C, Valerio L, Bonnet $\mathrm{H}$, et al. Factors associated with effective reassessment of antibiotic therapy on day 3. Med Mal Infect. 2013;43(3):123-7.

7. Ramirez JA, Cooper AC, Wiemken T, Gardiner D, Babinchak T. Switch therapy in hospitalized patients with community-acquired pneumonia: tigecycline vs. levofloxacin. BMC Infect Dis. 2012;12:159.

8. van Zanten $A R$, Engelfriet $P M$, van Dillen $K$, van Veen $M$, Nuijten MJ, Polderman $\mathrm{KH}$. Importance of nondrug costs of intravenous antibiotic therapy. Crit Care. 2003;7(6):R184-90.

9. Mertz D, Koller M, Haller P, Lampert ML, Plagge H, Hug B, et al. Outcomes of early switching from intravenous to oral antibiotics on medical wards. J Antimicrob Chemother. 2009;64(1):188-99.

10. Senn L, Burnand B, Francioli P, Zanetti G. Improving appropriateness of antibiotic therapy: randomized trial of an intervention to foster reassessment of prescription after 3 days. J Antimicrob Chemother. 2004;53(6):1062-7.

11. Carratala J, Garcia-Vidal C, Ortega L, Fernandez-Sabe N, Clemente M, Albero G, et al. Effect of a 3-step critical pathway to reduce duration of intravenous antibiotic therapy and length of stay in community-acquired pneumonia: a randomized controlled trial. Arch Intern Med. 2012;172(12):922-8.

12. Pestotnik SL. Expert clinical decision support systems to enhance antimicrobial stewardship programs: insights from the society of infectious diseases pharmacists. Pharmacotherapy. 2005;25(8):1116-25.

13. McGregor JC, Weekes E, Forrest GN, Standiford HC, Perencevich EN, Furuno JP, et al. Impact of a computerized clinical decision support system on reducing inappropriate antimicrobial use: a randomized controlled trial. J Am Med Inform Assoc. 2006;13(4):378-84.

14. Hulgan T, Rosenbloom ST, Hargrove F, Talbert DA, Arbogast PG, Bansal P, et al. Oral quinolones in hospitalized patients: an evaluation of a computerized decision support intervention. $J$ Intern Med. 2004;256(4):349-57.

15. Shojania KG, Yokoe D, Platt R, Fiskio J, Ma'luf N, Bates DW. Reducing vancomycin use utilizing a computer guideline: results of a randomized controlled trial. $\mathrm{J}$ Am Med Inform Assoc. 1998;5(6):554-62.

16. van der Sijs $\mathrm{H}$, Aarts J, Vulto A, Berg M. Overriding of drug safety alerts in computerized physician order entry. J Am Med Inform Assoc. 2006;13(2):138-47.

17. Dowell SF, Ho MS. Seasonality of infectious diseases and severe acute respiratory syndrome-what we don't know can hurt us. Lancet Infect Dis. 2004;4(11):704-8.

18. Rhew DC, Tu GS, Ofman J, Henning JM, Richards MS, Weingarten SR. Early switch and early discharge strategies in patients with community-acquired pneumonia: a meta-analysis. Arch Intern Med. 2001;161(5):722-7.

19. Lesprit P, Duong T, Girou E, Hemery F, Brun-Buisson C. Impact of a computer-generated alert system prompting review of antibiotic use in hospitals. $J$ Antimicrob Chemother. 2009;63(5):1058-63.

20. Lesprit P, Landelle C, Girou E, Brun-Buisson C. Reassessment of intravenous antibiotic therapy using a reminder or direct counselling. J Antimicrob Chemother. 2010;65(4):789-95. 
21. Vanstraelen K, Verhaegen J, Peetermans WE, Willems L, Spriet I. Stimulation of the i.v. to oral switch of bioavailable drugs by phone calls in a Belgian tertiary care hospital. Acta clinica Belgica. 2013;68(3):179-82.

22. Fraser GL, Stogsdill P, Dickens JD, Jr., Wennberg DE, Smith RP, Jr., Prato BS. Antibiotic optimization. An evaluation of patient safety and economic outcomes. Arch Intern Med. 1997;157(15):1689-94.

23. Fischer MA, Solomon DH, Teich JM, Avorn J. Conversion from intravenous to oral medications: assessment of a computerized intervention for hospitalized patients. Arch Intern Med. 2003;163(21):2585-9.

24. Marco P, Lopez-Abadia E, Lucas J. More on thromboprophylaxis: electronic alerts in hospitalized patients at risk of venous thromboembolism. Thromb Haemost. 2008;100(4):525-6.

25. Harris AD, Bradham DD, Baumgarten M, Zuckerman IH, Fink JC, Perencevich EN. The use and interpretation of quasi-experimental studies in infectious diseases. Clinical infectious diseases: an official publication of the Infectious Diseases Society of America. 2004;38(11):1586-91.

26. Wang HY, Chiu CH, Huang CT, Cheng CW, Lin YJ, Hsu YJ, et al. Blood culture-guided deescalation of empirical antimicrobial regimen for critical patients in an online antimicrobial stewardship programme. International journal of antimicrobial agents. 2014;44(6):520-7.

27. Jandoc R, Burden AM, Mamdani M, Levesque LE, Cadarette SM. Interrupted time series analysis in drug utilization research is increasing: systematic review and recommendations. Journal of clinical epidemiology. 2015.

28. van Daalen FV, Prins JM, Opmeer BC, Boermeester MA, Visser CE, van Hest RM, et al. A cluster randomized trial for the implementation of an antibiotic checklist based on validated quality indicators: the AB-checklist. BMC Infect Dis. 2015;15(1):134.

29. Hemming K, Haines TP, Chilton PJ, Girling AJ, Lilford RJ. The stepped wedge cluster randomised trial: rationale, design, analysis, and reporting. Bmj. 2015;350:h391.

30. Schuurmans MM, Tini GM, Zuercher A, Hofer M, Benden C, Boehler A. Practical approach to emergencies in lung transplant recipients: how we do it. Respiration. 2012;84(2):163-75. 